
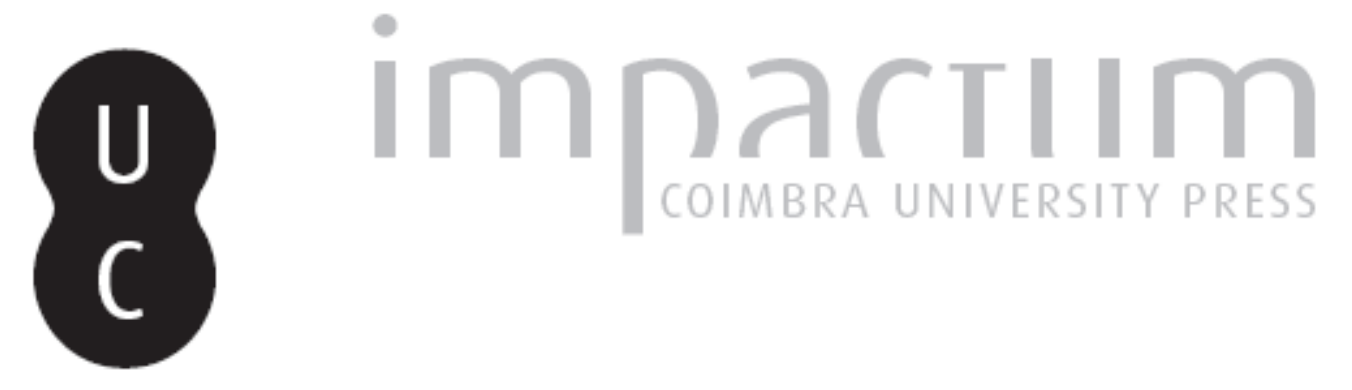

\title{
Serviço público e democracia: condições para um recentramento dos media de serviço público
}

\author{
Autor(es): $\quad$ Esteves, João Pissarra
}

Publicado por: Imprensa da Universidade de Coimbra

URL persistente:

URI:http://hdl.handle.net/10316.2/39262

DOI:

DOI:http//dx.doi.org/10.14195/2183-6019_2_4

Accessed : $\quad$ 26-Apr-2023 10:56:36

A navegação consulta e descarregamento dos títulos inseridos nas Bibliotecas Digitais UC Digitalis, UC Pombalina e UC Impactum, pressupõem a aceitação plena e sem reservas dos Termos e Condições de Uso destas Bibliotecas Digitais, disponíveis em https://digitalis.uc.pt/pt-pt/termos.

Conforme exposto nos referidos Termos e Condições de Uso, o descarregamento de títulos de acesso restrito requer uma licença válida de autorização devendo o utilizador aceder ao(s) documento(s) a partir de um endereço de IP da instituição detentora da supramencionada licença.

Ao utilizador é apenas permitido o descarregamento para uso pessoal, pelo que o emprego do(s) título(s) descarregado(s) para outro fim, designadamente comercial, carece de autorização do respetivo autor ou editor da obra.

Na medida em que todas as obras da UC Digitalis se encontram protegidas pelo Código do Direito de Autor e Direitos Conexos e demais legislação aplicável, toda a cópia, parcial ou total, deste documento, nos casos em que é legalmente admitida, deverá conter ou fazer-se acompanhar por este aviso.

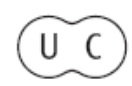


revista de comunicação,

jornalismo e espaço público

2

Periodicidade

Semestral

Imprensa da Universidade de Coimbra Coimbra University Press

\section{mediapolis}

tema

os desafios dos media

de serviço público

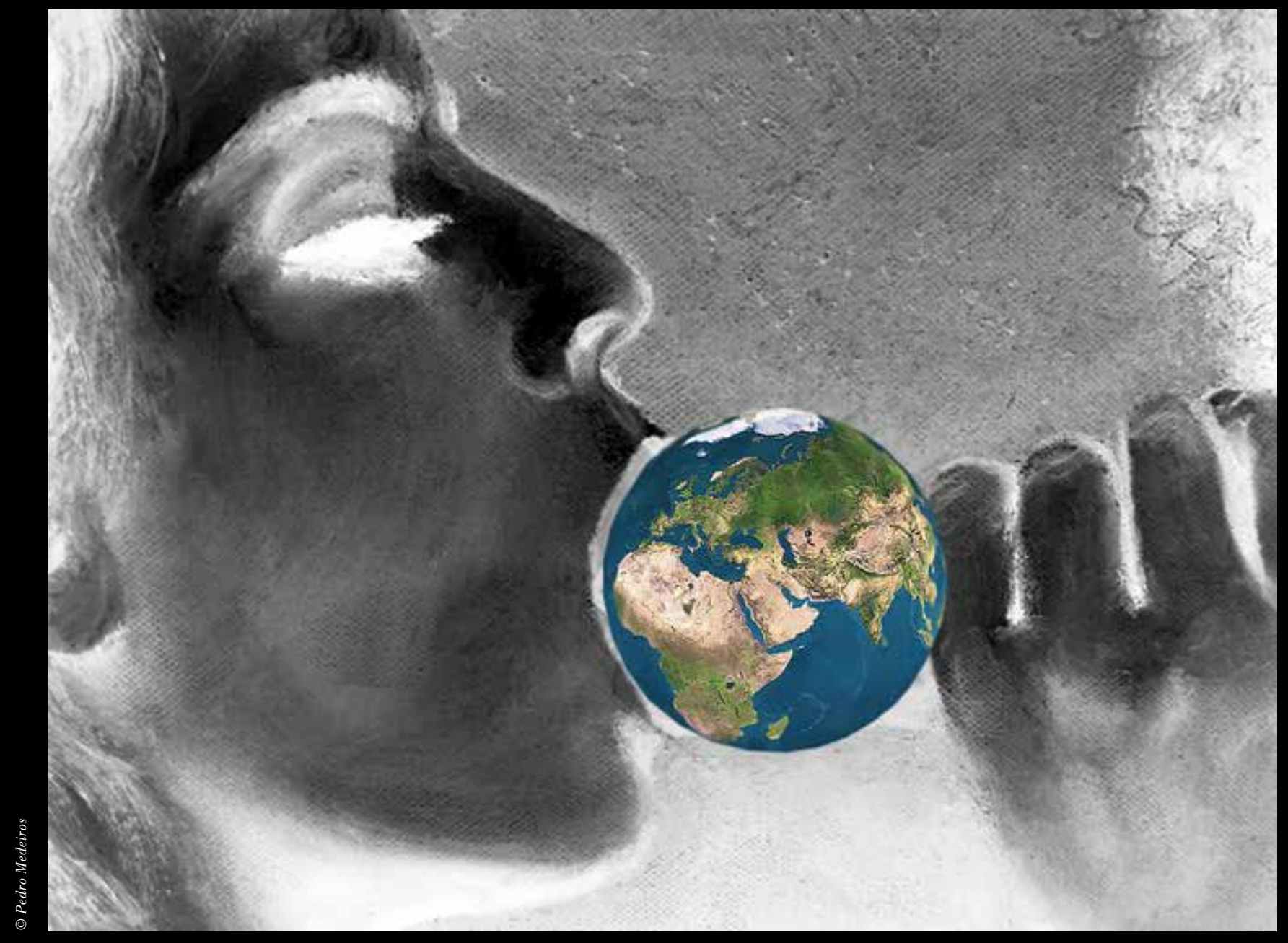




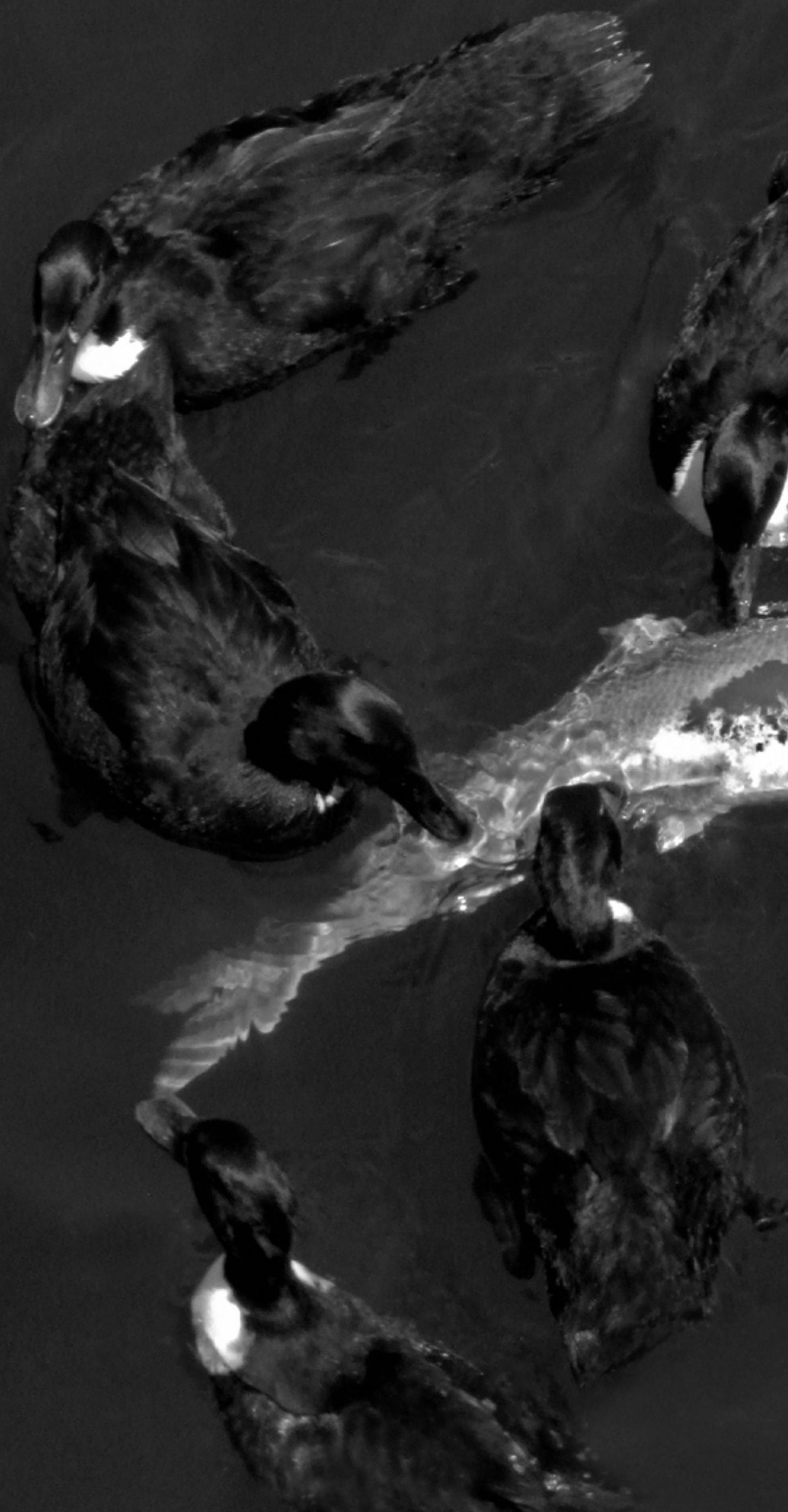




\section{Serviço público \\ e democracia:}

Condições para um recentramento

dos media de serviço público

\section{Public service and democracy: Requirements for the refocusing of the public service media}

\section{Resumo:}

A situação do sistema geral dos media nas nossas sociedades (os seus desequilíbrios) impõe uma requalificação do serviço público de comunicação, sobretudo por imperativos democráticos. Aqui são discutidas as condições para um recentramento deste serviço, considerando desafios a nível do seu funcionamento interno e outras matérias que dizem respeito às relações estabelecidas com outros setores importantes dos media (o empresarial privado, o de mercado social e o dos media cívicos). Por outro lado, e em face das presentes condições tecnológicas, a comunicação pública para ser pensada como central no sistema dos media não pode já restringir-se a um formato tradicional de serviço público (de radiodifusão), mas deve assumir uma escala mais vasta - abarcando as novas tecnologias e os chamados novos media. É a esta escala que o serviço público merece ser hoje pensado e, cada vez mais, não como uma questão apenas do domínio da política de comunicação, mas também e em primeiro lugar como uma matéria de cidadania, que se joga plenamente enquanto um direito de comunicação.

Palavras-chave: Democracia, comunicação pública, sistema dos media, mercado, serviço público de radiodifusão e dos media, direitos de comunicação.

\section{Abstract:}

The situation of the general media system in our societies (its imbalances) imposes a renewal of public service media, mainly due to democratic imperatives. The text discusses the conditions for a refocusing of the service, considering the emerging challenges in terms of its internal operations and other matters concerning the relationships with other major media sectors (private business, the social market and the civic media). On the other hand, and in view of present technological conditions, in order to critically consider public communication as a central element in a media system, the former can no longer be restricted to a traditional public service (broadcasting) format, but must assume a broader scale - embracing new technologies and the so-called new media. It is on this scale that public service needs to be considered today and, increasingly, not as just a matter of the realm of communication policy, but also and primarily as a matter of citizenship, fully enacted as a communication right.

Keywords: Democracy; Public Communication; Media System; Market; Public Broadcasting and Media Service; Communication Rights. 
Nos dias de hoje são muito diversificadas as razões que podem motivar uma discussão em torno do serviço público dos media. Mas, como sabemos, nem todas essas razões (e discussões) são necessariamente virtuosas - querendo com isto dizer o assumir de uma posição de defesa do serviço público. A situação portuguesa, desde longa data, é pródiga em episódios e situações deste tipo, de tal forma que talvez se possa mesmo afirmar que as discussões sobre serviço público de radiodifusão são, entre nós, quase sempre dominadas por uma espécie de instinto homicida - por vezes assumido frontalmente, noutras situações (quase sempre) manifestando-se por vias mais sinuosas e insidiosas.

Foi, porém, bem diferente o contexto que presidiu ao evento académico e debate público que estiveram na origem da publicação que agora é aqui dada à estampa: bem pelo contrário, foi num espírito de vigilância e sob o signo da denúncia crítica de manobras recentes em torno do serviço público de radiodifusão nacional - perigosas movimentações que, na ocasião, estavam em marcha. Esse motivo inspirador animou os organizadores do evento, assim como, estou certo, também a generalidade dos participantes e autores aqui reunidos: pela minha parte, aqui fica desde já a confissão de partilha desse espírito, como declaração de interesses e esclarecimento da motivação que me anima.

Já de seguida, passo a traduzir este interesse próprio numa pergunta simples, mas fundamental, que servirá aqui, ao mesmo tempo, como ponto de partida para uma reflexão sobre algumas matérias importantes relacionadas com comunicação pública. A questão é a seguinte:

De que forma pode o serviço público dos media contribuir, satisfatoriamente, para uma (maior) democratização do nosso sistema comunicacional?

A este propósito, dois esclarecimentos metodológicos prévios. Por um lado, a noção de sistema comunicacional é aqui utilizada num sentido abrangente, quase como sinónimo de comunicação pública: incluindo esta os media de serviço público, mas não se restringindo a eles. Por outro lado, no que diz respeito a um papel ativo em termos democráticos do serviço público de comunicação, assumimos que, para equacionar este, se torna necessário responder a um duplo desafio: 1) encontrar uma posição bem definida para o serviço público no quadro de uma ecologia geral dos media; e 2) clarificar a estrutura e forma de organização interna deste mesmo serviço (no que se refere pelo menos a um conjunto de grandes desafios que resultam da resposta à questão anterior).

Em Portugal (mas não só), quase se deixou de pensar a Política quando se fala de serviço público. São sobretudo os jogos estratégicos (também políticos, mas de uma outra política de letra minúscula) e os negócios que hoje dominam essa agenda de discussão; motivações diversas e objetivos difusos, desde finais dos anos 70 do século passado, têm convergido para pôr de pé uma cerrada barreira de fogo contra os media de serviço público (e a própria noção de serviço público num sentido mais amplo) (Hood, 1986: 60), numa aliança de franjas mais acirradas do espectro político em que esquerda e direita se encontram. Neste quadro, quando a questão da democracia chega sequer a ser equacionada, 


\section{Em Portugal}

(mas não só),

quase se deixou de

falar em Política

quando se fala de

serviço público quase sempre se limita a um ponto de vista meramente interno sobre o serviço público de radiodifusão; e a uma questão que se pretende ver dirimida no horizonte de uma disputa partidária pela atenção do público. Em boa verdade, neste contexto, até o termo "público" surge deslocado, pois o que aqui está em cena é, de facto, uma massa enquanto audiência de consumidores (leitores, ouvintes e espectadores dos media). Em certo sentido, não deixa de ser também política esta forma de perspetivar o funcionamento do serviço público, mas não pode é ser considerada propriamente como democrática, bem pelo contrário: visa uma ação dirigida ao público a partir do exterior e tem como objetivo, antes de mais, "influenciar este com o propósito exclusivo de uma manutenção do poder político constituído, ou pretende apenas extorquir do espaço público a lealdade de uma população que se encontra reduzida a uma massa" (Habermas, 1998: 460).

Em função de um propósito político de mais longo alcance, consideramos que a discussão da democracia no interior dos media de serviço público só fará sentido após uma prévia clarificação do papel (democrático) que cabe a este mesmo serviço no conjunto dos media nas nossas sociedades. $\mathrm{Ou}$, dito de outra forma, a democracia em termos comunicacionais tem como significado a comunicação pública, cujo horizonte, porém, só pode ser definido pelos media em geral e não exclusivamente pelos $m e$ dia de serviço público. Assim, pensar um papel relevante do serviço público em termos democráticos não pode deixar de significar a atribuição a este serviço de um lugar central no sistema geral dos media; significando isto muito mais do que apenas uma questão de democraticidade (interna) do serviço público de comunicação e, sobretudo, equivalendo isto a muito mais do que àquilo a que hoje temos acesso em termos de comunicação pública.

Feito este trajeto, somos chegados a uma segunda questão essencial:

\footnotetext{
Como pode ser definida essa centralidade do serviço público de radiodifusão, em função das relações que os media deste tipo é suposto estabelecerem com os restantes media (os demais setores/
} 


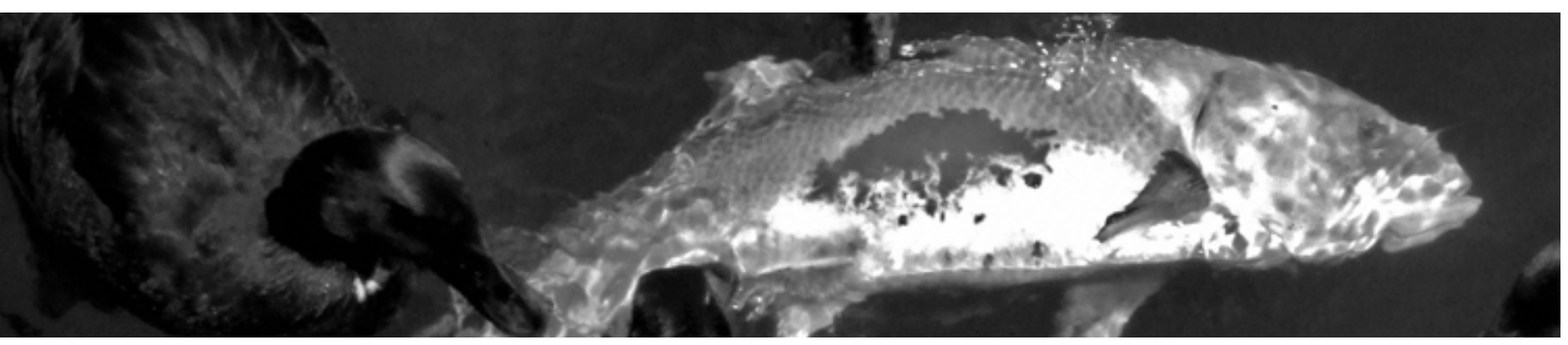

subsistemas do sistema geral dos media das nossas sociedades)?

Em primeiro plano, a relação que pretendemos equacionar - a mais nevrálgica e, também, a mais crítica - é a do serviço público com o setor empresarial dos media, os chamados media mainstream, que se encontram organizados numa lógica privada e que têm por base o lucro.

Se a equação que estabelecemos para valorizar a democracia determina a centralidade do serviço público no sistema geral dos media, isto significa então que temos aqui, desde logo, um problema. Sem dúvida que esse lugar pertence hoje ao setor empresarial privado - com uma série de problemas conhecidos que daí decorrem, nomeadamente em termos políticos. Mas não é o serviço público, só por si, que tem a possibilidade de inverter esta situação: trata-se de um problema de vontade política (e de capacidade de decisão), que se situa muito para além do funcionamento dos media de serviço público. Uma outra questão é a importância (e a necessidade) de estes media se encontrarem preparados para uma tal mudança: a sua organização e forma de funcionamento devem poder justificar a atribuição dessas responsabilidades reforçadas, ou seja, devem tornar plausível a ideia de que a sociedade tem alguma coisa a ganhar (e todos nós de um modo geral) com esse reordenamento de posições a nível do sistema global dos media.

Os media de serviço público devem estar preparados para contribuir diretamente para essa alteração, pois, se a questão é aqui de vontade política, trata-se então, também, e antes de mais, de um problema de consciência cívica - a condição básica que permite tornar operacional uma capacidade de influência efetiva sobre os órgãos políticos legítimos (de decisão). O que se pretende afirmar, pois, é que esta mudança não dispensa em nenhuma circunstância um apoio cívico decidido; e este, nos dias de hoje, é indissociável de uma consciência pública a que os media não são sem dúvida indiferentes.

A centralidade do serviço público no quadro do sistema geral dos media apenas poderá ser alcançada numa sociedade preparada para esse objetivo, que mostre disponibilidade em se bater pela democracia; e não é de

\section{A centralidade do}

serviço público no

quadro sistema

geral dos media

apenas poderá

ser alcancada

numa sociedade

preparada para

esse efeito 
esperar que sejam os media comerciais os promotores dessa coragem cívica, ao contrário dos media de serviço público: aliás, essa é mesmo, de certo modo, a sua obrigação, atendendo à responsabilidade de que se encontram investidos.

Não pretendemos afirmar que o setor empresarial dos media é, em si mesmo, um obstáculo para a democracia, mas já diferente é a questão da sua posição cada vez mais central no conjunto do sistema dos media - esta sim, hoje, potencialmente ameaçadora para a generalidade dos outros setores (todos os demais tipos de media). Mas importa sempre recordar que esse lugar corresponde, na verdade, a uma concessão, por assim dizer, que as nossas sociedades vêm conferindo aos media comerciais - ou seja, a responsabilidade última desta situação cabe a todos nós (seja de forma intencional, seja por omissão).

$O$ engodo que tem sido utilizado para perpetuar esta realidade dá pelo nome de "liberdade de escolha" (de que supostamente o mercado, e só ele, seria o guardião); mas, como explica Jean Seaton, trata-se de uma ideologia absurda e com alguns perigos muito sérios:
“A radiodifusão comercial é baseada não na venda de programas a audiências, mas na venda de audiências à publicidade. (...) $\mathrm{O}$ resultado é muito provavelmente uma menor variedade do tipo de programas que muitos de nós veem algumas vezes, e que alguns de nós veem a maior parte do tempo, mas que não atingem grandes ratings de audiência. Todos nós, ocasionalmente, somos membros de minorias. Assim, pois, as vítimas da concentração dos media são a variedade, a criatividade e a qualidade, ao mesmo tempo que a proliferação de canais na mão de um grupo restrito de operadores, "livres" pelas políticas governamentais de obrigações de variedade de serviço público, muito provavelmente arrastará um agravamento da situação. "Escolha" sem uma direção positiva é um mito, por muito que o mercado ofereça mais - mas só mais do mesmo" (Curran \& Seaton, 1991: 308 e 309).

Não esquecemos o outro registo de funcionamento de um setor empresarial dos media hegemónico que, para operacionalizar a lógica do lucro, tem por base os serviços de radiodifusão pagos. Só que, em termos políticos, nem sequer podemos falar aqui de uma outra face da moeda, pois a ameaça para a democracia que resulta de um serviço de radiodifusão cada vez mais dependente de um sistema de canais fechados é também muito séria:

"a privatização da informação, da cultura e do entretenimento pode muito bem criar uma sociedade de dois níveis, de ricos e "pobres, no que respeita a estes recursos. Um desenvolvimento deste tipo acabará por minar os princípios democráticos fundamentais sobre os quais assenta o serviço público de radiodifusão" (Scannell, 1992: $321)$.

Resolver estes problemas passa por encontrar um registo mais adequado para o funcionamento deste setor dos media, de modo a que a próprio se possa afirmar com algo realmente positivo para a democracia, a que seja possível associar algum contributo concreto para uma comunicação pública mais 
democrática. Como explica James Curran, em condições de uma justa regulação do sistema geral dos media, o setor privado empresarial pode trazer esse contributo, na medida em que a ele se associa a expectativa de uma representação mais equilibrada do espectro político (salvaguardando a presença das posições mais de direita), bem assim como de um reforço da função de watchdog dos media:

"mesmo a sua independência em relação ao governo sendo um equívoco, a sua vulnerabilidade à influência do governo assume, porém, uma forma diferente daquela das organizações que formalmente se encontram ligadas ao Estado - ainda que modesta, esta diferença representa uma medida de segurança" (Curran, 1991: 110).

Como já antes afirmado, a questão da democracia da comunicação pública é um problema que envolve o conjunto do sistema dos media, isto significa, portanto, que terá de ser no interior deste sistema que devem conjugar-se diferentes contribuições, de modo a se atingir esse desejado resultado final. O todo (também aqui) é sempre algo que está para além das partes (ou da soma destas): nenhum segmento específico dos media (nem o próprio serviço público) reúne em si a totalidade dos atributos e a força necessários para garantir uma democraticidade satisfatória da comunicação pública. Neste sentido, o contributo democrático que se pode esperar dos media comerciais corresponde, de facto, a uma complementaridade com o serviço público - e não a uma rivalidade ou, muito menos, a uma posição de superioridade. Podemos imaginar, muito concretamente, um exemplo de qualidade e diversidade que os media comerciais observam a nível do serviço público e que, depois, eles próprios podem emular fazendo valer a sua maior independência em relação ao Estado, e assumindo a função de $w a$ tchdog como um verdadeiro exercício de cidadania.

Outras complementaridades, mas ainda de acordo com este mesmo sentido geral, devem ser equacionadas entre o serviço público e os outros dois mais importantes segmentos do sistema global dos media - os media cívicos e os media de mercado social. Recordamos o propósito transversal a todo este conjunto de inter-relações: elas visam contribuir para uma maior democraticidade dos media na sua totalidade.

Quanto a estes dois setores - e ao contrário daquilo que equacionámos para os media empresariais privados -, o desafio que hoje se coloca é o do seu fortalecimento, a criação de condições para que os media destes dois tipos possam assumir (ou recuperar) uma presença mais forte na comunicação pública dos nossos dias. Este fortalecimento em nome da democracia pode ser justificado por motivos genericamente distintos num caso e no outro, embora ambos muito relevantes: no caso dos media de mercado social é de salientar o seu compromisso primacial com o pluralismo da comunicação (a diversidade), enquanto em relação aos media cívicos, aquilo que talvez importe mais valorizar seja a facilitação do próprio acesso aos media e à comunicação pública - o acesso mais direto por parte de um certo número de atores sociais, na condição, pois, de sujeitos de discurso (sem necessidade de mediações de outro tipo). 
Quando pensamos no fortalecimento destes dois setores, equacionamos complementarmente alguma forma de apoio por parte do serviço público e, de modo ainda mais preciso, políticas públicas de apoio à comunicação que tenham em atenção as ameaças que hoje pairam sobre estes setores; a menor das quais não será, por certo, e mais uma vez, a posição de hegemonia que o setor empresarial tem vindo a assumir sobre o conjunto dos media. As legislações anti-concentração que, nos nossos dias e nas sociedades ocidentais, se tornaram por assim dizer como que obrigatórias, encontram a sua justificação primordial numa defesa resoluta desses valores democráticos essenciais que se considera ameaçados. $\mathrm{O}$ caso português a este nível, no entanto, não é de modo algum paradigmático, como se traduz de forma muito precisa no retrato rápido que se segue:

\footnotetext{
"A diversidade de fontes e de conteúdos é formalmente valorizada em princípio, sendo expressa nos mais importantes instrumentos legais e incorporada nos programas e discursos governamentais.
}

\section{Puxar pelos media}

cívicos e pelos

media de mercado

social significa

para o serviço

puíblico, também,

a possibilidade de

este vir a firmar

mais solidamente

a sua centralidade

no sistema geral

dos media

\begin{abstract}
Contudo, esta preocupação assumida não se traduz em ação pragmática. Os grupos de media estão autorizados a desenvolver as suas estratégias de negócio sem barreiras efetivas à sua expansão vertical e horizontal, e os canais de televisão generalistas podem tornar-se de facto operadores de entretenimento, abandonando assim as suas obrigações originais" (Sousa e Silva, 2009: 99).
\end{abstract}

Puxar pelos media cívicos e pelos media de mercado social significa para o serviço público, também, a possibilidade de este vir a firmar mais solidamente a sua centralidade no sistema geral dos media, na medida em que, de um ponto de vista democrático, os setores referidos cumprem uma importante função de complementaridade em relação ao próprio serviço público. Por muito que o pluralismo e a livre publicitação sejam para este também princípios axiais, dificilmente no funcionamento do serviço público dos media o grau de concretização destes princípios poderá rivalizar com aquilo que é oferecido pelos media de mercado social e os media cívicos. 
A maior dificuldade em conseguir potenciar sinergias (democráticas) a este nível talvez esteja no facto de existir aqui uma certa falta de sincronia operacional entre os diversos planos mediáticos (e todos estes setores); por exemplo, na medida em que o serviço público é apenas de radiodifusão e os outros dois setores têm presença preferencialmente a nível de imprensa e de internet - com os jornais locais e regionais, para os media de mercado social, e as publicações oficiais dos mais diversos tipos de associações e organizações sociais, para os media cívicos.

É verdade que as novas tecnologias de informação e comunicação vieram baralhar bastante estas divisões, mas não é certo que as alterações produzidas sejam suficientes, só por si, para definir uma nova arrumação do sistema geral dos media. Se as vozes em defesa de um civic commons no âmbito da internet cada vez mais hoje se fazem ouvir (Coleman \& Blumler, 2009: 179 e 180), isso também significa que as novas tecnologias mais do que trazerem uma resposta democrática para os problemas da comunicação pública, ameaçam elas mesmas tornar-se um problema suplementar e, por este motivo, a necessidade urgente do seu próprio ordenamento em termos democráticos.

Depois de equacionadas estas condições necessárias à afirmação da centralidade do serviço público no sistema geral dos media das nossas sociedades, é chegado o momento de passar à discussão de outras questões importantes relacionadas com este mesmo objetivo, mas agora de ordem mais interna, por assim dizer, que envolvem a organização propriamente dita do serviço público dos media.

A ligação entre estes dois planos de análise é absolutamente necessária e, nesse sentido, ajuda se conseguirmos encontrar um certo fio condutor para as diversas questões mais específicas que discutiremos em seguida. A pergunta que pode dar-lhe visibilidade é a seguinte:

Quais os grandes desafios internos a que o serviço público dos media deve responder para assumir de uma forma satisfatória as responsabilidades inerentes à sua posição num lugar central do sistema geral dos media dos nossos dias? Como deve ele organizar-se internamente para poder reivindicar - e assumir - essa posição nuclear no plano da comunicação pública?

Vontade e capacidade de decisão política pressupõem discurso e comunicação, mas não é de palavras vazias ou de enunciados vagos que se espera uma resposta a estas questões. Discursos sobre estas matérias sem densidade pragmática, bem sabemos que têm sido moeda corrente entre nós, para alcançar propósitos performativos obscuros, quase sempre perfeitamente antagónicos à intencionalidade expressa. Em referência aos problemas que temos aqui discutido, esta deceção pode ser traduzida do seguinte modo: palavras e mais palavras que se encadeiam e atropelam para nomear a democracia, mas que apenas têm servido para criar uma situação cada vez mais desconfortável em termos democráticos para o serviço público dos media - e a comunicação pública. A incerteza quanto à virtude democrática deste setor dos media não é hoje em menor grau, bem pelo contrário - como afirma mais 
uma vez Jean Seaton, ao recordar a quebra do consenso fundamental que esteve na origem da filosofia de serviço público de comunicação (e dos seus diferentes modelos operacionais), que assumia ser "a regulação do Estado a melhor garantia para a independência e a responsabilização dos serviços de radiodifusão" (Curran \& Seaton, 1991: 299).

Discutiremos, em seguida, ainda que brevemente, um conjunto de tópicos da organização interna do serviço público que se afiguram especialmente críticos no que diz respeito à pretensão de reordenamento do sistema geral dos media antes equacionado. Trata-se de matérias que, do nosso ponto de vista, podem hoje dar uma dimensão propriamente pragmática a qualquer discurso que queira assumir a defesa do serviço público dos media. E são, ao mesmo tempo, estas matérias os grandes desafios que nesta área hoje se colocam aos decisores políticos, bem assim como à sociedade no seu conjunto e a todos nós enquanto cidadãos - como responsáveis últimos, em democracia, pela formação da vontade política. Alias, não restam muitas dúvidas de que um grande número de problemas quanto ao serviço público dos media com que hoje continuamos a debater-nos se fica a dever a uma situação, por assim dizer, de falência cívica. E, também, por certo, todos estaremos mais ou menos conscientes de que a possibilidade de qualquer inversão do presente estado de coisas no domínio da comunicação será precisamente por aqui que tem de começar.

Talvez o primeiro grande desafio com que hoje o serviço público de radiodifusão se debate, quando pensamos na sua afirmação no sistema geral de media, diga respeito à questão da propriedade. $\mathrm{O}$ modelo tradicional de serviço público, como é sabido, é o de uma propriedade também ela pública, mas já de há algum tempo a esta parte que se encontra em aberto uma discussão sobre outras possibilidades a este nível. Será possível, ou até desejável, um serviço público dos media de propriedade privada ou de propriedade mista? Também entre nós este assunto conheceu mais recentemente alguns desenvolvimentos importantes no plano do debate político, embora persistam fundadas dúvidas se o seu sentido alcançou algum efeito realmente esclarecedor.
Não podemos deixar de enquadrar esta questão num tempo em que se vem afirmando, e de uma forma bastante aguda, a consciência da importância das práticas regulatórias no que se refere ao funcionamento dos media em geral, assumindo a este nível a questão da propriedade um significado especial, inclusive nesse aspeto tão básico como é o de um escrutínio quanto à honorabilidade pessoal dos próprios proprietários dos meios; hoje,

\footnotetext{
"a lei pode ser usada para restringir uma série de matérias inerentes ao negócio dos media, a primeira das quais é a da propriedade, e isto pode mesmo incluir a seleção de quem é considerado uma pessoa idónea para assumir a propriedade de um canal ou de um jornal privado." (Frost, 2013: 500).
}

Perante este quadro, no caso de Portugal, começar uma discussão sobre esta matéria pondo em cima da mesa (ou por debaixo da mesa, talvez mais propriamente) a possibilidade de se vir a privatizar o serviço público de radiodifusão numa lógica 
essencialmente empresarial, perfilando-se de imediato na primeira linha de interessados grupos económicos estrangeiros (de países sem quaisquer créditos dignos de nota em termos de democracia), há que reconhecer que não é propriamente a situação mais auspiciosa para uma matéria desta importância. Os fatores de entropia assim criados foram tantos, logo à partida, que o assunto nem chegou propriamente a ser objeto de um verdadeiro debate, ficando talvez para a história apenas o registo de mais um caso exemplar dos tais discursos e enunciados vazios - ou falseados de modo grosseiro, talvez mais precisamente, dado aqui a vacuidade pragmática se encontrar ao serviço, de facto, de uma performatividade ardilosa (de intenções não declaradas).

Porém, é um desafio pensar a possibilidade de se verem equacionadas outras hipóteses - mesmo com o risco de estas se apresentarem como bastante extravagantes, à luz do padrão do mais recente debate internacional sobre estas matérias. Mas vamos assumir que Portugal é um país com uma capacidade especial de surpreender, e quem sabe se não estaremos aqui na

\section{Num mundo}

cada vez mais

globalizado

a fórmula de

uma espécie de

franchising de

"grandes marcas"

de serviço público

dos media terá

pernas para

andar? senda de algo mesmo muito original; hoje, em nome da cartilha neoliberal, as nossas empresas públicas são gloriosamente vendidas a empresas públicas de países estrangeiros, e a isto se dá o nome de "privatizações", por que não pensar a possibilidade de no serviço público dos media poder vir a surgir também uma mãozinha estrangeira? Mas, para baralhar os dados (neoliberais), assumindo que o primado não será agora de ordem económica, mas político e democrático, ficamos à espera das manifestações de interesse por parte de possíveis operadores estrangeiros. Será que a britânica BBC, a ARD alemã ou a France Télévision, só para dar alguns (bons) exemplos, terão algo a dizer sobre este assunto?... Num mundo cada vez mais globalizado como o nosso, esta fórmula de uma espécie de franchising de "grandes marcas" de serviço público dos media terá pernas para andar? Para serviços públicos quase irrelevantes (como o nosso), para os quais as questões de qualidade nunca se impuseram como um critério de distinção fundamental, esta pergunta pode ser muito mais do que retórica e assumir um sentido que 

um serviço público que, portanto, deve ser capaz de criar internamente condições para um escrutínio sobre a qualidade das suas próprias produções e um sistema de incentivo permanente à inovação - não são valores que se mostrem compatíveis com um serviço público unitário ou tendencialmente uniformizado, falemos tanto a nível de televisão como de rádio. "Se a radiodifusão é nos dias de hoje defensável enquanto serviço público, ela só o poderá ser enquanto um serviço para o público" (Scannell, 1992: 317): este é o significado de um serviço público de radiodifusão seriamente comprometido com a democracia, que se quer assumir numa posição central no atual sistema dos media, e que nessa medida não se pode ver reduzido a uma expressão exígua (desde logo, a começar pela oferta de serviços que deverá ser capaz de garantir).

Outro desafio sério com que o serviço público dos media se tem debatido ao longo do tempo diz respeito aos seus mecanismos de direção. Matéria absolutamente crítica para uma afirmação da legitimidade democrática destes media, tanto mais por não ser hoje ainda uma questão que se possa considerar resolvida - também entre nós, apesar de alguns mais recentes avanços que permitiram já, pelo menos, a descolagem de um modelo extremamente governamentalizado (mais de acordo com aquela que é a nossa tradição, de um serviço oficial de media).

O valor democrático primacial aqui em jogo e que importa preservar é o da não governamentalização do serviço público. Quer o modelo histórico anglo-saxónico (BBC) de um serviço civil neutral, quer o modelo germânico de base representativa (regional e corporativo) constituem alternativas válidas a este nível; não é por acaso que os dois são normalmente apresentados como os grandes paradigmas do serviço público europeu (Potschka, 2012). Mas também quanto a esta matéria, a nossa experiência diz-nos que os modelos formais são apenas parte do problema; uma parte importante, mas indissociável de outra de ordem mais prática: a existência de uma verdadeira cultura cívica que permita operacionalizar de uma forma virtuosa os modelos abstratos. No caso português, somos chegados a um ponto em que é possível afirmar que não será tanto por carência de modelos que os problemas persistem, mas sobretudo pela ausência dessa cultura (ou a sua fragilidade pelo menos).

Para os serviços públicos de radiodifusão mais consolidados, a questão do perigo de governamentalização já há muito que deixou de se apresentar com um caráter crítico (mesmo permanecendo como um problema adormecido), enquanto para nós não restam dúvidas de que ainda hoje continua a constituir um desafio de primeira ordem; e mais em concreto, um obstáculo à afirmação inquestionável deste serviço no quadro geral dos media, numa posição central como grande referência democrática. A ideia decorre da conclusão principal apresentada num grande estudo de referência sobre esta matéria: "uma maior independência política dos serviços públicos de radiodifusão, se for assegurada já hoje, pode livrar estes serviços de terem de enfrentar no futuro ameaças maiores à sua própria existência" (Hanretty, 2011: 196).

Mais complexa ainda é a situação no que diz respeito às teias de 
influência social que se tecem em torno dos media de serviço público e que podem, no limite, acabar mesmo por capturar todo o seu funcionamento. Falamos do perigo de a informação, os programas culturais ou os de entretenimento se tornarem um fator de proteção ou de favorecimento de determinados grupos ou setores sociais, de elites ou fações, etc.; algo que pode acontecer não necessariamente por efeito deste ou daquele modelo de direção do serviço público, ou mesmo, eventualmente, por influência das entidades diretivas competentes, mas como resultado de complexas relações de influência que podem estender-se pelos níveis intermédios de decisão (ou até mesmo pelos níveis inferiores), e que poderão ser - são normalmente de facto - determinantes no que diz respeito aos inputs finais da programação, a nível de enunciados e das formas discursivas concretas oferecidas pela comunicação pública televisiva e radiofónica.

Se um serviço público exemplar depende de uma direção isenta, não depende em menor grau de um desempenho imparcial a nível da sua programação - afastando lógicas de
Se um serviço

público exemplar

depende de uma

direção isenta,

não depende em

menor grau de

um desempenho

imparcial a

nível da sua

programação favorecimento de uns em detrimento de outros (orientações políticas, grupos sociais, tendências culturais, etc.). Disto depende, também, absolutamente, a possibilidade de afirmação do serviço público como referência para o presente sistema dos media. Sendo certo que, neste caso (como em certo grau também em todos os anteriores), o meio mais eficaz para enfrentar este perigo se encontra muito mais no exterior do que no interior do próprio serviço público: depende do poder crítico e da capacidade de vigilância da sociedade em geral e do próprio público (do serviço público) em particular. Mesmo os exemplos mais paradigmáticos de serviços públicos de radiodifusão na Europa têm nesta verdade insofismável uma lei absoluta do seu sucesso:

"Os dois sistemas [britânico e alemão] podem ser melhorados. A representação da radiodifusão na Alemanha deve incluir um maior número de representantes dos novos movimentos sociais, ao mesmo tempo que a diversidade ideológica e cultural deve ser adotada na Grã-Bretanha enquanto 
um objetivo explícito de serviço público. Mas o aperfeiçoamento das regras e estruturas da radiodifusão apenas pode alcançar melhoramentos limitados. Isto porque a natureza do diálogo público conduzido através do serviço público de televisão reporta sempre ao debate público mais amplo que tem lugar na sociedade" (Curran, 1991: 107).

Finalmente, um breve apontamento relacionado com o desafio tecnológico com que, também, o serviço público dos media hoje por todo o mundo se debate. De acordo com muita literatura, as novas tecnologias de informação e comunicação constituem, porventura, a principal ameaça que recai sobre estes media, pelo que elas representam como subversão, por assim dizer, e corrosão dos alicerces da própria noção de serviço público. Importa recordar que, na origem da grande crise que se abateu sobre este serviço, nas últimas décadas do século passado, se encontra uma revolução tecnológica (das telecomunicações) que veio pôr em xeque uma das premissas fundamentais da própria noção de serviço público neste âmbito:

"O cabo e os satélites puseram fim à escassez do espectro radioelétrico. Num certo sentido, este espectro continua hoje a ser tão escasso como era nos anos 20 , no entanto com as novas tecnologias o seu uso tornou-se mais eficiente e, em consequência, passou a ser possível fazer o licenciamento de mais canais. A legitimação tecnológica de um monopólio público da radiodifusão tornou-se, deste modo, difícil de manter" (Donders, 2012: 13).

Os efeitos desta revolução tecnológica no domínio das telecomunicações sobre o serviço público não podem, porém, ser dissociados da concomitante deriva liberal e entronização dos mercados que, a partir dessa mesma época, tomou conta das sociedades ocidentais. Aliás, só mesmo em função deste signo liberal é que o desafio tecnológico se assume como ameaça (um perigo) para o serviço público de comunicação; este é o seu enunciado:

\begin{abstract}
"Os novos desenvolvimentos no campo dos media na Europa [mas não só], como a televisão digital ou os media online, tornam-se uma realidade pela simples razão de eles serem fortemente influenciados pelas necessidades da indústria, pelas preocupações financeiras e por um marketing intensivo (...). Tal como no passado, esta necessidade industrial tem sido associada à emergência das ideologias neoliberais que professam a reestruturação e modernização da economia e, na verdade, a mercantilização do setor da comunicação pública" (Papathanassopolus \& Negrine, 2011: 36).
\end{abstract}

Por um lado, há a considerar um importante efeito subversivo que as novas tecnologias de informação e comunicação têm sobre todo o ecossistema tradicional dos media, de que a extraordinária pulverização de audiências não será, por certo, o problema menor. Por outro lado, é uma nova ecologia dos media nascida já da ação destas novas tecnologias que vem reclamando, e cada vez mais intensamente, a presença ordenadora 
de algo parecido com um serviço público de comunicação - de forma, precisamente, a que se torne possível a preservação de um sentido democrático essencial para o conjunto. A deslocação do conceito tradicional de serviço público de radiodifusão para o de um serviço público dos media (mais abrangente) traduz já o assumir deste desafio, mesmo que esta nova designação permaneça ainda muito indefinida quanto ao seu significado. Podemos, no entanto, distinguir dois tipos de recorte que, de certo modo, definem já hoje o seu conteúdo: um serviço público de edição (public service publisher), que está essencialmente preocupado em responder às transformações que atingem as tradicionais empresas (públicas) de radiodifusão com a sua entrada no mundo digital (Donders, 2012: 2123), e um civic commons que está direcionado de forma mais específica para o universo global da internet. Já antes nos referimos em passagem a este serviço, mas agora de forma mais precisa:

"Um civic commons no ciberespaço tem por objetivo criar uma estrutura estável que possa concretizar mais eficazmente o potencial democrático dos novos media interativos. Isto requer a criação de uma entidade pública inteiramente nova, concebida para forjar novos laços entre a comunicação e a política e para pôr em conexão de forma mais efetiva as vozes das pessoas com as atividades quotidianas das instituições democráticas" (Blumler \& Coleman, 2001: 16).

À dificuldade de um "serviço público dos media que já existe, mas para o qual não há ainda um consenso teórico e político quanto aos seus fundamentos" (Donders, 2012: 23), acresce uma outra dificuldade a nível da sua operacionalização que diz respeito à necessidade de conseguir uma conjugação de forças (energias cívicas) à escala planetária, a dimensão em que hoje, cada vez mais, o funcionamento da comunicação pública se processa; isto ao mesmo tempo que, como sabemos, toda a lógica de existência dos serviços públicos permanece ainda, nos nossos dias, quase exclusivamente confinada aos limites das fronteiras dos Estados nacionais.

Não existe nenhuma solução acabada para este tipo de desafio, aliás, para os vários problemas que as novas tecnologias colocam à comunicação pública dos nossos dias - mas a situação não é muito diferente, em boa verdade, relativamente a todos os outros desafios do serviço público que aqui equacionámos. Hoje talvez seja já mais nítida a perceção de que "a abundância de espectro radioelétrico (a multiplicação de canais e circuitos) não é a mesma coisa do que pluralismo de conteúdos, de programação e de software" (Barber, 2003: 34); e, como afirma Michael Tracey, isso ajudou a consolidar melhor a convicção de que "o interesse público não deixou de existir apenas por hoje termos ao nosso dispor o cabo de banda larga" (1995: 126). Não encontramos ainda as respostas para todos os problemas com que nos deparamos, ou a saída para a crise do serviço público, mas a mobilização de energias em torno destes objetivos é hoje já bastante expressiva, o que nos permite olhar para o futuro com (mais) algum otimismo. 
Por outro lado, sabemos que este género de situações é de certo modo típico da própria natureza da democracia: um caminho que se faz caminhando e que apenas se pode fazer desse modo. Ou, dito de outra maneira, a afirmação do serviço público de comunicação numa posição central do sistema dos media nos nossos dias, mais do que depender de uma resposta precisa e indiscutível a cada um dos desafios aqui equacionados, deve começar poder ser sustentada por uma clara consciência desses problemas e pela disponibilidade de para eles se procurar as melhores respostas políticas, no quadro de um inequívoco compromisso com a nossa democracia - uma democracia entendida, propriamente, como uma forma de vida e não apenas como um solução de governação.

Neste sentido, o serviço público que sempre foi considerado, antes de mais, como uma questão de política de comunicação, perante as ameaças que sobre ele hoje recaem, merece ser equacionado - e prioritariamente - como uma questão de direitos, um direito de comunicação (communication entitlement) no pleno sentido da palavra:

\footnotetext{
"O igual acesso para todos a um amplo e variado leque de serviços comuns de informação, entretenimento e cultura, através de canais que possam ser recebidos em todo o território, merece ser pensado como um direito de cidadania importante nas sociedades democráticas de massa. Este é um meio essencial - talvez o único no presente - pelo qual os conhecimentos e os prazeres comuns numa vida pública partilhada podem ser preservados como um bem social para o conjunto da população. Como tal, esse direito deve ser defendido dos seus inimigos" (Scannell, 1992: 346).
}

Este é o sentido essencial do otimismo moderado com que observamos a delicada situação que o serviço público de comunicação hoje atravessa - bem assim como a nossa democracia. Ponto de vista a que não podemos deixar de juntar, por outro lado, uma certa dose de ceticismo, que estas palavras desencantadas de Denis McQuail por assim dizer exprimem:

\begin{abstract}
A performance dos media reflete as imperfeições da sociedade muito mais do que as suas próprias falhas. $O$ público, na sua qualidade de audiência, também tem a sua responsabilidade e nós não podemos estar seguros de que, mesmo com mais oportunidades, o público se regozije com a chegada de 'melhores' media ou abra os braços a formas de accountability que requerem da sua parte algum esforço mais continuado. É também ilusório pensar que melhores media conduzem necessariamente a uma melhor sociedade" (1997: $528)$.
\end{abstract}

Este olhar desencantado sobre a relação media-sociedade assume um âmbito muito abrangente, mas não está em causa a sua pertinência, nem a sua atualidade, para nos ajudar a entender um pouco melhor toda esta crise do serviço público aqui em discussão. 


\section{Bibliografia}

Barber, B. R. (2003). Which technology and which democracy? In H. Jenkins, \& Thorburn, D. (eds.), Democracy and New Media (pp. 33-47). Cambridge, Mass.: The MIT Press.

Blumler, J. G., \& Coleman, S. (2001). Realising Democracy Online: A civic commons in cyberspace. London: Institute for Public Policy Research.

Coleman, S., \& Blumler, J. G. (2009).

The Internet and Democratic Citizenship: Theory, practice and policy. Cambridge: Cambridge University Press.

Curran, J. (1991). Mass Media and Democracy: a Reappraisal. In J. Curran \& M. Gurevitch, (eds.), Mass Media and Society (pp. 82-117). London: Edward Arnold.

Curran, J. \& Seaton, J. (1991). Power Without Responsibility: The press and broadcasting in Britain, $4^{\text {th }}$ ed. London: Routledge.

Donders, K. (2012). Public Service Media and Policy in Europe. Basingstoke: Palgrave Macmillan.

Frost, C. (2011). Journalism Ethics and Regulation, $3^{\text {th }}$ ed. Abingdon: Routledge.
Habermas, J. (1998). Facticidad y Validez: Sobre el derecho y el Estado democrático de derecho en términos de teoria del discurso. Madrid: El Trotta (orig. 1992).

Hanretty, C. (2011). Public Broadcasting and Political Interference. Abingdon: Routledge.

Hood, S. (1986). Broadcasting and the public interest: from consensus to crisis. In Golding, P.; Murdock, G. \& Schlesinger, P. (eds.). Communicating Politics: Mass communication and the political process (pp. 55-66). New York: Holmes \& Meier.

McQuail, D. (1997). Accountability of media to society: principles and means. In European Journal of Communication, 12 (4), 511-529.

Papathanassopoulus, S. \& Negrine, R. (2011). European Media: Structures, policies and identity. Cambridge: Polity Press.

Potschka, C. (2012). Towards a Market in Broadcasting: Communications policy in the UK and Germany. Basingstoke: Palgrave Macmillan.

Scannell, P. (1992). Public service broadcasting and modern public life In P. Scannell, P. Schlesinger, \& C.
Sparks (eds.). Culture and Power. London: Sage, 317-348.

Sousa, H., \& Silva, E. C. (2009). Keeping up appearances: regulating media diversity in Portugal. The International Communication Gazette, 71 (1-2), 89-100.

Tracey, M. (1995). The role of listeners and viewers in the future of broadcasting. In B. Groombridge, \& J. Hay, (eds.), The Price of Choice: Public service broadcasting in a competitive European market place (pp.124-127). London: John Libbey Publishing. 